\title{
Algumas reflexões sobre elementos de base e estratégias da Análise do Discurso
}

Some considerations on basic points and strategies of Discourse Analysis

\section{Ida Lúcia Machado Universidade Federal de Minas Gerais - UFMG}

\section{Resumo}

Este artigo propõe algumas reflexões sobre a Análise do Discurso. Elas se concentram em primeiro momento sobre a associação explicito e implícito dos diferentes enunciados, para daí abordar a interdisciplinaridade constitutiva da Análise do Discurso. Em seguida, indaga-se sobre o porquê das estratégias discursivas e buscase definir o que seria a estratégia de captação inserida em um gênero especial de discurso: o político e, mais especificamente, aquele que se refere às trajetórias de dois ex-presidentes da República, um brasileiro e outro francês. Finalmente a terceira reflexão toma por objeto o gênero narrativa de vida. A questão que se coloca então é a de saber se este gênero, quando sustentado pela voz dos dois políticos objeto da pesquisa, tem uma função argumentativa. $\mathrm{O}$ artigo tem por objetivo interrogar alguns pontos básicos da Análise do Discurso e, sobretudo, suscitar ainda reflexōes sobre o que é proposto.

\section{Palavras-chave}

Análise do Discurso, Estratégias discursivas, Discurso político, Narrativas de vida. 


\section{Abstract}

This paper aims at reflecting on some key elements in Discourse Analysis. Such a reflection focuses, at first, on the association of explicit and implicit elements taken from different statements. Further on, this analysis leads to the concept of interdisciplinarity as an inherent characteristic of Discourse Analysis. On the same token, the study makes an attempt to understand why some particular discursive strategies have been used in the statements under analysis in order to find out what type of capturing strategy is prevalent in a particular discourse genre, more specifically, the political discourse of two former presidents, one from Brazil and the other from France. Finally, this paper sets off to investigate the genre "Narrative of Life" as a way to examine whether such a genre, when supported by the politicians' voices observed in the study, can display an argumentative function. Finally, this paper aims at questioning some key elements in Discourse Analysis, considering the effects which can emerge from such a reflection.

\section{Keywords}

Discourse Analysis, Discursive Strategies, Political Discourse, Narratives of Life. 


\section{Reflexões preliminares}

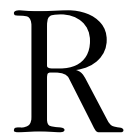
efletir que, em enunciados diferentes, há palavras sob palavras é algo que atrai minha atenção, desde que entrei em contato com os princípios da Pragmática na Universidade de São Paulo e isso bem antes de pensar em estudar a Análise do Discurso, propriamente dita. Em outros termos, refiro-me aqui às práticas que levam os sujeitos falantes a buscar o sentido dos enunciados - todos eles - dentro de uma determinada situação e contexto, buscando pistas no explícito das palavras que levem ao seu implícito. Vê-se que o estudo de categorias da linguística textual contribuiu muito para minha futura formação como analista do discurso.

Exponho, então, minha primeira reflexão e, para ilustrá-la, tomo as palavras do título que escolhi para o presente artigo: em sua parte explícita é apenas um título como tantos outros, que tenta ser descritivo, mas, em sua parte implícita, carrega consigo todo um universo linguageiro, que reflete a trajetória de muitas décadas de pesquisas em estudos da linguagem: "Seja dizendo bom dia, seja fazendo uma conferência, há sempre, sob a aparência tranquila das palavras, uma torrente de significaçóes implícitas". (CHARAUDEAU, 1995, p.23) ${ }^{1}$

Observe-se o uso do léxico no título em pauta. Nele foram utilizados termos como "Algumas", "Análise do Discurso", "reflexôes", "estratégias", "elementos de base": eles mostram que o sujeito-enunciador ${ }^{2}$ ao elaborar tal título, já deixa transparecer sua estratégia discursiva: a de convidar o futuro leitor da revista (sujeito-interpretante) a vir descobrir o que essas palavras guardam em seu âmago. Assim, antes mesmo que o artigo seja lido, no enunciado que o anuncia, uma instância ou um sujeito enunciativo tenta captar a atenção do leitor ou futuro leitor. Tal sujeito é responsável pela distribuição das palavras do título e deixa pairar sobre elas um ar de convite mais ou menos misterioso. Aliás, o título, como todo o título se equilibra entre o explícito e o implícito. Algo foi enunciado, mas esse algo não basta. $\mathrm{O}$ corpo do artigo é que vai tentar clarear a junção de palavras que o anunciam. 
Qual a razão de tal reflexão? É simples: todos os enunciados, ou atos de linguagem ou ainda atos comunicativos, jogados na arena discursiva, não são aleatórios: eles têm uma razão de ser. "Salvo em interjeições ou em atos falhos", poderão retrucar. Insisto, porém: nem mesmo aí existe a aleatoriedade. As palavras da língua, usadas para a formação desses diferentes atos, já vêm carregadas de intençōes e, como afirmam Anscombre e Ducrot (1983), oferecem aos seus usuários diferentes maneiras de se exprimir para influenciar seus interlocutores. Em suma, o sujeito-enunciador emprega diferentes palavras, escolhendo-as em suas diferentes memórias: a discursiva, aquela que se refere às situaçôes de comunicação por ele vividas ou pressentidas e a memória dos signos da língua, na qual vai ou deve se comunicar (CHARAUDEAU, 2004, p.19-20). Assim agindo, de modo consciente ou não, o sujeito-enunciador (ou falante) tenta defender uma opinião, refutar ou aceitar a do outro, se justificar, explicar, suplicar, ironizar, mostrar seu desagrado ou sua alegria, etc., para mostrar que existe e de uma forma ou outra está buscando interagir no intrincado mundo comunicacional.

Desse modo, observar a reunião do explícito e do implícito nos atos de linguagem é algo curioso e também inquietante. Afinal de contas, o que é um analista do discurso? Um detetive de palavras? Aquele que busca colocar um sentido em tudo? Os seres comunicantes não seriam mais felizes se conformando apenas com os explícitos dos ditos e escritos do outro? Na certa. Mas, seriam mais alienados também.

$\mathrm{O}$ analista do discurso observa, escuta e lê o mundo ao seu redor. Sua profissão deseja trazer alguma luz para os diferentes usos linguageiros de uma dada sociedade. Trata-se de um estado de ser ou de um modo de vida um pouco perigoso, pois, quando alguém que pensa se situar no alto de sua ciência e, assim espera captar tudo de todos os atos de linguagem que escuta ou lê - seu direito e todos seus possíveis avessos - esse ser irá fatalmente se perder em labirintos cujas saídas são difíceis, senão impossíveis. O que pode salvá-lo em suas investigaçôes de caráter científico? As metodologias analítico-discursivas, com seus respectivos instrumentais teóricos. Elas ajudam o pesquisador a não se perder em voos vertiginosos, graças à linguística que está em sua base.

Essa reflexão leva a outra. Nem todos os instrumentais teóricos analíticodiscursivos são provenientes da linguística. A Análise do Discurso (AD) foi criada tendo por base o fator interdisciplinar (de certo modo, todas as análises do discurso - algumas mais que outras - foram criadas assim). 
Assim, ao longo dessas décadas em que estudei discursos por meio da $\mathrm{AD}$, vi certas polêmicas nascerem, sumirem e depois renascerem no âmbito desses estudos. A controvérsia a qual gostaria de me referir diz respeito, curiosamente, aos elementos que formam as bases da $A D$. Desde Pêcheux (anos 60), que considero, como tantos outros colegas, o criador da $\mathrm{AD}$, essa disciplina começa a operar baseada na diversidade, a partir de uma reunião de conceitos vindos da linguística, da história e da psicanálise. Ou seja: a $A D$ primeira já se mostra fundamentalmente interdisciplinar e conta com subsídios teóricos vindos de outras áreas.

Embora o que foi dito seja hoje de conhecimento geral, é sempre bom que alguém aqui ou ali o relembre. E é sempre bom também lembrar que existem várias metodologias de $\mathrm{AD}$ e que todas são válidas. Uma convivência pacífica se estabeleceu em torno dessa diversidade, como o provam os congressos de $\mathrm{AD}$, entre outros. Observe-se, no caso da $\mathrm{AD}$ de tendência francesa, que há certas metodologias que mantiveram uma grande proximidade com as teorias de Pêcheux e depois Foucault; no entanto, há outras que se distanciaram mais desse fulcro. Porém, todas estão ligadas, de um modo ou de outro, à teoria fundadora: umas com amarras fortes, outras com fios transparentes.

Através dos anos, a $\mathrm{AD}$ continua a resistir e a inovar o campo da linguística discursiva, navegando contra correntes turbulentas ou se beneficiando de ventos favoráveis e isso desde sua criação e posterior chegada ao Brasil.

A metáfora marinha acima utilizada pode parecer excessiva. Mas o fato é que a $\mathrm{AD}$, qualquer que seja sua metodologia, e apesar de todo seu sucesso, ao lidar com diferentes instrumentais de pesquisa, é por vezes ainda vista por alguns membros da comunidade linguística como um ponto nevrálgico, inserido em tais estudos. Esses problemas aparecem justamente por causa de sua interdisciplinaridade e da amplitude de corpora com os quais ela trabalha. Por essa razão, os pesquisadores de $\mathrm{AD}$ são muito solicitados (artigos, palestras, cursos) em diferentes faculdades ou programas de pós-graduação: Direito, Administração, Comunicação, Engenharia, Medicina, Psicologia, entre outros.

Há de se reconhecer que após a chegada ao Brasil, a AD evoluiu e cresceu muito, ultrapassando barreiras e fronteiras que alguns dos fundadores de suas diferentes metodologias não puderam transpor. Há de se reconhecer também que é o hibridismo dessa disciplina que faz com que ela tenha tanto sucesso.

Um linguista como Charaudeau, ao conceber sua metodologia de análise do discurso, trabalhou com dados vindos da linguística, da pragmática, da 
semiótica greimasiana, da sociologia, da psicologia social, das teorias da argumentação e com conceitos vindos de filósofos e teóricos da linguagem. Observem o que afirma Charaudeau (1983, p.7), no livro em que divulga sua teoria e a necessária interdisciplinaridade desta:

Esta dificuldade em verificar, reproduzir, formalizar, enfim, em colocar o objeto linguístico à distância e a fixar os instrumentos de análise explica, para nós, que não é possível haver um itinerário único e forçado no que diz respeito à formação do pensamento linguístico. Para provar o que foi dito, teríamos o fato de que os linguistas modernos vêm de horizontes de pensamento diverso, tais como, por exemplo, a filosofia, a literatura, os estudos de línguas estrangeiras, a gramática e a filologia, e ainda a sociologia, a psicologia e a matemática. Defender o ponto de vista de quem afirma que um percurso histórico deve se primar pela unicidade no domínio da linguística seria mais o resultado de uma decisão do que de uma constatação. Evidentemente, não negamos a existência da herança de pensamentos: toda teoria, como toda palavra, se define tomando por ponto de comparação outras teorias, outras palavras; mas, esta herança passa pelo sujeito produtor da teoria ou da palavra; o que significa, em resumo, que existem tantos percursos teóricos quanto tantos sujeitos teorizadores. (Evidentemente há interseções entre esses percursos).

"Há interseçôes entre estes percursos". Destaco este enunciado da citação acima, já que ele me parece ser de suma importância, não apenas para a metodologia de Charaudeau como também para todas as outras metodologias de AD. Ele mostra que há necessárias e evidentes interações entre a $\mathrm{AD}$ e os caminhos que ela percorre: em minha opinião, é assim que se forma uma linguistica discursiva, aquela que governa as abordagens e análises em $\mathrm{AD}$. Note-se que a palavra interseção foi compreendia em seu sentido lato, aquele que aponta para a interdisciplinaridade ou o cruzamento de diferentes teorias, vindas de diferentes campos de estudo.

Continuo minhas reflexôes: de Pêcheux a Charaudeau (e entre os dois teóricos incluo os diversos estudiosos da $\mathrm{AD}$ ), os conceitos evoluíram bastante, o que é normal. Tal evolução diz respeito à contribuição que a $\mathrm{AD}$ do Brasil 
transmitiu à europeia (após assimilá-la e adaptá-la), como também ao fluxo social-político que muda com o passar dos anos e aponta, assim, para outros corpora. O caso do linguista Charaudeau ilustra esse fato: por muito tempo, ele ignorou a ideologia política e os discursos que enfocassem os ditos, escritos e as ações desse ou daquele político. Por essa razão, sua metodologia semiolinguística foi por muitos considerada como a de uma $\mathrm{AD}$ politicamente neutra, o que pode ter minimizado seu valor. Mas tal apreciação é injusta. A AD, segundo Charaudeau, é ligada ao social: logo, ela pode tratar de todos os discursos que circulam em uma sociedade.

Cabe lembrar que, na França, durante um certo período (pós Pêcheux), a vida política, se não foi perfeita, também não ofereceu muito material a ser questionado. E cabe lembrar que a AD de Charaudeau, cuidadosamente elaborada, tentou se demarcar da AD de Pêcheux. Mas as coisas foram mudando. Assim, Charaudeau lançou um livro, em 2005, em que fala sobre as máscaras do poder político. No entanto, durante a passagem de Sarkozy na presidência desse país, de 2005 a 2012, houve uma grande mudança nos temas por ele abordados e esse teórico adotou corpora claramente políticos em seus últimos escritos. O que quero dizer, ao tomar como exemplo Charaudeau, é que as mudanças sociais pelas quais passa uma nação, em determinados períodos, governam os pontos de vista e abordagens acadêmicas no âmbito da AD.

De forma talvez repetitiva, o que busco com este e com todos os meus escritos sobre $\mathrm{AD}$ é defender a sua diversidade metodológica, e a sua interface com outras disciplinas. Sem isso, a AD morreria ou, no mínimo, se enfraqueceria. Ela se fecharia sobre si mesma e passaria a trabalhar com documentos não autênticos, que buscassem apenas justificar a teoria. Ela não seria mais uma disciplina aberta e viva, em que se trabalha com o discurso por meio de documentos autênticos, como a vida em sociedade os produz neste ou naquele momento.

A linguagem não é propriedade exclusiva de um único campo de estudos. "No âmbito de estudos analítico-discursivos, ela será objeto de uma análise hermenêutica, heurística e retórica que interpreta, relaciona e analisa os diferentes usos linguageiros". (SANTOS, 2012).

Dentro desse prisma, exporei algumas noções de estratégia no próximo segmento. A palavra "estratégia" vem do discurso de guerra e pode fazer parte das metodologias de AD que se conjugam bem com as teorias da argumentação. 


\section{Segundas reflexões: estratégias discursivas}

Tanto Charaudeau $(1983,1992,2005)$ quanto Maingueneau (1998) ligam a $\mathrm{AD}$ ao teatro. Essa visão me é particularmente agradável: como estudiosa da linguagem e de suas artimanhas $(1985,1988)$ sempre considerei que havia algo de encenado nas trocas comunicativas, sem saber definir bem o que seria. $\mathrm{A} A \mathrm{D}$ trouxe a resposta: essas trocas são oriundas de um jogo entre parceiros da comunicação, que buscam influenciar uns aos outros com seus atos de linguagem ou enunciados, não hesitando, para tanto, em assumir diferentes papéis e a usar diferentes estratégias.

Charaudeau (1995, p.22) expõe claramente o que considera como estratégias do discurso. Ele as coloca em número de três: a estratégia de legitimidade, a da credibilidade e a da captação. Procópio Xavier (2010) traduziu, adaptou e detalhou as afirmações do teórico, segundo a transcrição abaixo:

1. Estratégia de Legitimidade - Ela é externa ao sujeito falante e se origina do estatuto mais ou menos institucional do locutor. É a legitimidade que dá o poder de dizer. Ela resulta da constatação de uma adequação entre um ato de fala, uma situação e a posição social do seu autor.

2. Estratégia de Credibilidade - Para ser entendido, o locutor deve ser julgado apto a dizer a verdade. É preciso que ele se mostre capaz de provar sua capacidade em lidar com restrições do contrato. Essas estratégias tendem a comprovar a habilidade do locutor em "saber dizer".

3. Estratégia de Captação - É a atitude que consiste em tocar o afeto do auditório, em provocar nele certo estado que seja favorável a uma visada de influência do sujeito falante. Essas estratégias tendem a emocionar o interlocutor a partir de procedimentos como: entonação de voz, procedimentos de sugestão, de conivência, de humor, entre outros. (PROCÓPIO-XAVIER, Sintese elaborada para Seminário apresentado na disciplina Teorias do Discurso, ministrado por MACHADO, I.L., no PosLin/ FALE/UFMG, $1^{\circ}$ semestre 2010).

A estratégia de captação é muito usada por uns e outros em diferentes situações comunicativas. Cativar o leitor ou o ouvinte é algo que trabalha não apenas com o explícito dos ditos, mas que vai além. Existem certos procedimentos que podem 
provocar, mais que outros, certos imaginários nos diferentes interlocutores e que se ligam a uma ou outra emoção; nesse sentido cabe lembrar que alguns atos de linguagem são mais propícios que outros para a entrada da emoção.

Assim, uma carta administrativa, formulários acadêmicos no qual se solicita a aprovação da banca de uma defesa de dissertação ou tese, pedidos de auxílio para participações de eventos endereçados a órgãos de fomento, entre tantos outros documentos que são ritualizados por regras e configurações dos dispositivos institucionais de uma sociedade, são impermeáveis à presença da emoção. Tais documentos podem ser considerados como parte de um gênero rotineiro, isto é: um gênero mais fechado que outros e que pede um estilo direto, o mais objetivo possível (MAINGUENEAU, 2004). Desse modo, marcas de afetividade, humor, ironia ou zombaria não são bem-vindas nesse gênero. Imaginemos uma bula de remédio na qual a ironia apareça, por exemplo; ela perderia sua identidade genérica e eliminaria, ao mesmo tempo, as estratégias de legitimidade e credibilidade da bula. $\mathrm{O}$ documento ligado ao gênero rotineiro é um documento sério, no sentido de que não comporta nenhum jogo lúdico.

No entanto, como já anunciei acima, há gêneros que se abrem para a inclusão dos procedimentos que levam o auditório (ou os leitores, expectadores ou ouvintes) à emoção: cito ainda na esteira de Maingueneau (Op. cit.) os discursos religiosos e os publicitários.

Do mesmo modo, o discurso de um político busca a adesão de um auditório e, para tanto, não hesita em trazer para si elementos que nele podem desencadear a emoção; por vezes, eles aparecem antes ou depois de argumentos mais pragmáticos do político, tais como: trabalhar para aumentar o crescimento econômico da nação, preservar a natureza, etc. Os discursos de campanhas políticas recorrem com frequência a estratégias tanto de sedução quanto de persuasão e, entre as primeiras, podem conter elementos que geram a emoção no auditório: sentimentos como a piedade para com a dor de seus próximos, tristeza diante de uma catástrofe natural ou outra, etc.

Entre os sujeitos que praticam o discurso político é comum tal tipo de apelo, que pode também se apresentar de forma eufórica, alegre. Isso ocorre quando são exaltados os ganhos que um governo trouxe para a vida social, a redução de taxas, o controle efetivo da inflação, o verde recuperado em uma cidade, etc. "A comunicação política tem, em primeiro lugar, a ambição de persuadir, mas é sabido que ela não pode negligenciar a tentativa de seduzir o cidadão." (CHARAUDEAU, 1995, p. 23). 
Assim, chega-se à conclusão de que todas as três estratégias supracitadas fazem parte da comunicação, vista como um todo. Há sempre o desejo, por parte do sujeito que as emprega, de poder influenciar o outro de alguma maneira.

Lochard e Boyer (1998, p. 34) falam das Estratégias de sedução utilizadas para despertar a parte emotiva do leitor, ouvinte ou expectador e explicam que essa estratégia se faz acompanhar por efeitos de dramatização ou efeitos lúdicos.

Observemos a seguir dois casos que ilustram a presença da estratégia citada: o primeiro é impregnado de efeitos lúdicos e, o segundo, de efeitos de dramatização.

$1^{\circ}$ caso. No agora findo governo Sarkozy, tornou-se uma quase moda ou hábito a divulgação, pela imprensa francesa people, de fatos ligados à vida particular desse político, como se ele fosse uma estrela de cinema. Isso pode acontecer em outros países, entretanto, a ênfase dada à vida privada de Sarkozy, durante todo seu governo, foi por demais exagerada, no caso de um presidente da república cuja imagem a priori deve ser a de um homem responsável, e não a de alguém mundano. O governo em questão recebeu de alguns de seus opositores a denominação de governo bling-bling.

Os atos e gestos do presidente em pauta e da primeira dama deste presidente começaram a ser expostos ao público de forma excessiva, talvez para fazê-lo desviar os olhos de um governo cheio de falhas, mas que tinha a sua frente um casal, no mínimo, curioso: ele, nervoso, febril, agitado; ela, calma, sorridente, desfilando pelo mundo como na época em que foi top-model; uma mulher de grande beleza e elegância, nascida e criada em berço de ouro.

Para ilustrar o uso da estratégia de captação e sedução do público, basta abrir ao acaso algum livro francês que tem como tema o casal em pauta. Foi o que fiz com um deles: o livro de Benaïm e Azéroual, intitulado Carla et Nicolas. La véritable histoire, publicado em 2008. Na página dezenove do livro, lê-se o seguinte:

Antes mesmo de saber se algo iria se passar entre estas duas fortes personalidades, Johana Fath supõe qual será o resultado dessa noite [em que o futuro casal foi oficialmente apresentado pelo publicitário Jacques Séguela, em um local luxuoso da noite parisiense]. Por mais de uma vez, ela já tinha testemunhado os talentos de sedutores de sua amiga que ela conheceu, ainda adolescentes, nas pistas de esquiar de Courchevel. (Tradução minha.) 
Note-se o estilo elegante e sofisticado dado a esses ditos, no qual os autores do livro comentam como foi organizado o primeiro encontro do presidente Sarkozy com sua futura esposa e os elogios que a ela são feitos: uma mulher dotada de um enorme potencial de sedução e que convivia com pessoas da alta esfera da sociedade francesa. $\mathrm{O}$ pequeno trecho oferece duas comprovações para o que foi dito: (i) Carla é apresentada como amiga de Johana Fath (cujo discurso é aqui relatado), neta do famoso e rico costureiro francês dos anos 50, 60, Jacques Fath e (ii) quando adolescente, Carla já frequentava estações de esqui, como Courchevel, reservadas à alta sociedade. O que se pode notar é que as quatro linhas do trecho transcrito jogam com o fator divertir o leitor, jogar poeira dourada em seus olhos.

O trecho pode ser considerado como lúdico, nesse sentido: ele não faz rir, porém pode fazer o leitor sonhar com o mundo brilhante da alta sociedade, frequentado pelo casal. Isso acontece graças ao uso de termos próprios às narrativas fantasiosas que aparecem quando mundos encantados constituem a base de uma história.

$2^{\circ}$ caso. Para ilustrar o efeito de dramatização, volto-me para a figura de Lula, expresidente do Brasil. Tomo por base um trecho de um de seus inúmeros discursos, mais especificamente, o que foi realizado em 12 de julho de 2007, na cidade de Recife - em Pernambuco, em prol das áreas de saneamento e de urbanização desse estado.

Uma outra coisa que nós precisamos cuidar, neste país, Eduardo [Campos, governador de Pernambuco], eu sei que houve um tempo em que a esquerda não gostava que a gente falasse isso, isso era atrasado, até falar em pátria era atrasado, João Paulo [prefeito de Recife]. Então, na década de 70, se a gente falasse pátria "esse cara é conservador". Naquele tempo não tinha a palavra neoliberal, era outra coisa qualquer, de direita. Para mim tem uma coisa sagrada que é a família. Se a família estiver bem, tudo está bem, se a família estiver mal, tudo está mal. Cuidar da família é permitir que a família cuide dos seus, porque senão as pessoas não se cuidam e acham que o Estado vai cuidar. O Estado nem sabe onde a pessoa mora, quem sabe é a mãe e o pai. Portanto, cuidar, acabar com a desagregação da estrutura da família brasileira, aquele negócio de 
filho brigar com o pai, de pai brigar com mãe, ninguém fica feliz dentro de casa, as pessoas não querem chegar em casa porque sabem que é um inferno. (LULA, Discurso "Lançamento do PAC em áreas de saneamento e de urbanização do estado de Pernambuco". In: KAMEL, A., 2009, p. 231)

Note-se no trecho acima transcrito, a curiosa reflexão que Lula faz sobre o léxico, analisando quais palavras não eram bem aceitas em certas épocas de nossa história e, a partir daí, mostrando como a língua determina o que pode e deve ser dito e como o uso linguageiro é comandado por fatores políticos e sociais: reflexão de linguista! A partir dessas considerações, Lula chega ao cerne de sua mensagem: ele quer falar da família, já que essa palavra e o que ela encerra não são mais considerados como valores ultrapassados, pelo menos para ele e no seu governo.

Dentro de um projeto de fala, a digressão feita por Lula é bem articulada e são curiosas às voltas que ele dá até inserir, com segurança, em sua fala, a palavrachave de um de seus temas preferidos e já utilizados em inúmeros discursos.

Longe do espaço glamurizado mostrado no $1^{\circ}$ caso, temos aqui a fala de um presidente que não esconde suas origens humildes e que se volta para preocupaçōes bem realistas: os dramas familiares. O discurso de Lula dramatiza a situação de famílias humildes do Brasil, a exemplo do que ele próprio viveu, a família desamparada - note-se a menção à mãe e ao pai - não sabe mais que rumo tomar. O ideal de família modesta, trabalhadora, digna e feliz, no seio da massa brasileira, é uma utopia, e Lula sabe disso. Em seu discurso, o então presidente emprega axiológicos com uma carga emocional forte, a do verbo "brigar" e a do substantivo "inferno". Lula usa um estereótipo bem brasileiro e cristão, saído de um pensamento pronto e acabado, próprio de uma religião maniqueísta: a vida familiar deveria ser o céu, mas é o inferno para a maior parte dos trabalhadores brasileiros. Lula diz que, nessas situações, o Estado aparece para os membros de uma família desagregada, como o pai que resolverá todos os problemas econômicos que essa desagregação ocasionará. Mas, não é bem esse papel que ele, naquele momento preciso, enquanto presidente, pretende assumir. Lula avança então um argumento simples, por meio de um topos (ANSCOMBRE, 1995, p. 39; AMOSSY, 2006, p. 13), ligado aos valores cristãos, o que poderia ocasionar a argumentação seguinte (DUCROT, 1972, 131-141): 
Quem não respeitar a família não progredirá na vida $\rightarrow$ conclusão $n a ̃ o-p$ Quem respeitar a família progredirá na vida $\rightarrow$ conclusão $p$

Entre não-p e $p$, vê-se que Lula age de um modo que ousarei chamar de socrático: ele lança um problema e duas opçôes para resolvê-lo - evidentemente, a segunda é a melhor. Mas ele não diz isso claramente e deixa ao trabalhador escolher qual opção seguirá, mas, sem esperar que o Estado que o presidente representa, interfira nessa decisão.

Ao propor esse raciocínio simples - mas que tem grandes chances de atingir a massa de pessoas modestas que devem ter ido escutá-lo - vejo o seguinte possível interpretativo (mas existem outros): Lula evoca seu éthos paternal, como o presidente do povo, para logo depois rejeitá-lo: há um certo conflito em sua fala, por causa do interdiscurso, no sentido de conjuntura de discursos que se atravessam, transpassam em sua fala. Esse interdiscurso parece se chocar com o que Lula diz. Isso o leva, enfim, a renegar a condição de pai que ele quis assumir no início de seu primeiro mandato, quando foi criticado pela oposição de não resolver o problema da miséria no país, fazendo as reformas que agora aparecem (e que motivam o discurso citado). Na verdade, diziam que a distribuição da cesta básica iria criar um Estado de assistidos e os seus inúmeros problemas continuariam a existir. Já no segundo mandato, diante das reformas efetivas que seu governo realiza, ele pode contestar essa crítica. O éthos paterno de Lula continua, mas agora ele é um pai severo, cuja obrigação é a de apenas apontar diferentes caminhos para o filho escolher, em vez de tomar decisōes em seu lugar. Assim, é possível notar a presença de estratégias de sedução em sua fala: elas se ligam a efeitos teatrais trágicos. Há um tom de ameaça na voz do pai que pode levar o filho a uma reação.

De modo geral, o uso de estratégias de sedução busca estabelecer uma cumplicidade cultural com o leitor. Sem dúvida, o apelo à estereotipagem ou à voxpopuli participam dessa visada de aproximação do sujeito-enunciador com seus ouvintes ou leitores. Tal visada aponta para os sentimentos e crenças de um povo. O discurso de Lula deve ter comovido, de algum modo, as famílias que o escutavam, naquele momento.

$\mathrm{Na}$ França, esse tipo de discurso não teria o mesmo efeito, e o tema família unida $=$ família feliz não apareceria em discursos de políticos de esquerda. Assim, no dia 6 de junho de 2012, assistindo no canal de televisão TV5, às 20:30 horas, o programa Eléctions législatives 2012 - Campagne Officielle, programa de 
propaganda política de diferentes partidos franceses para as eleições legislativas, vi que a expressão "família unida" aparecia, sim, mas na fala de uma representante do UMP, partido de direita do ex-presidente francês, Nicolas Sarkozy, o que não deixa de ser curioso. Mesmo no próprio Brasil, conforme o lugar e a situação, o tema familia indissolúvel não iria captar muitos partidários, já que as opiniōes, costumes e crenças mudam de um estado para outro, de uma cidade para outra. Enfim, o que enfatizo no caso dessa estratégia discursiva assumida por Lula é o jogo operado entre o que já foi dito e o não-dito.

Ora, para compreender o sentido desse e de outros enunciados estratégicos, o sujeito-interpretante deve efetuar uma busca em sua memória discursiva, verdadeiro arquivo de interpretações suscetíveis de serem aplicadas aos diferentes discursos que escuta ou lê.

No próximo segmento, ainda dentro do tema estratégias, serão abordados enunciados assumidos por Lula e Sarkozy ou que a eles se referem e que desvelam fios de suas vidas particulares, fora do mundo político. Chega-se, assim, à narrativa de vida.

\section{Terceira reflexão: a narrativa de vida como estratégia argumentativa}

O que é a narrativa de vida? Para responder, tomo por base outros escritos por mim produzidos. Assim, afirmei (MACHADO, 2009, p. 108) que a narrativa de vida é um curioso gênero que circula nas Ciências Sociais e da linguagem e explico que ela surgiu como metodologia entre 1918 e 1920, em uma densa obra organizada por dois sociólogos da Escola de Chicago (Thomas e Znanieckzi), na qual é analisada a situação de integração ou não-integração de imigrantes poloneses fora de seu país.

Na perspectiva de uma abordagem que reúne a sociologia e a etnografia, o pesquisador Daniel Bertaux introduz esse tema de pesquisa na França, em 1970. A partir daí, a narrativa de vida ganha diferentes apelações: história de vida, narrativa de si mesmo, autobiografia. Outros gêneros, categorizados como Memórias e Ensaios e mesmo certas obras poéticas contêm também narrativas de vida, ainda que essas apareçam esparsas ou apresentadas sem obedecer a uma cronologia rígida. ${ }^{3}$ Nessas produções, é latente um diálogo interno entre o narrador e as outras vozes que atravessam seus ditos. 
Cabe lembrar que os relatos de vida fazem vender livros e chamam a atenção atualmente, até mais que os romances ou outros gêneros.

Porém a questão que busco responder desde que iniciei uma pesquisa sobre a narrativa de vida é: ela pode ser considerada como uma estratégia discursiva e, mais que isso, uma estratégia argumentativa?

Se a argumentação for pensada somente como o fruto de debates em que os raciocínios lógicos se afrontam, a resposta será negativa. Mas existe uma outra visão da argumentação, que poderá dar mais subsídios ao questionamento acima proposto. Trata-se da que foi adotada por Amossy (2006, p.33), na qual a teórica propõe uma divisão da a argumentação em visadas argumentativas e em dimensões argumentativas. Assim, no primeiro caso, seriam argumentativos os enunciados que têm uma visada persuasiva e aparecem em momentos de discussão ou debate, em que pelo menos dois pontos de vista diferentes são confrontados: cada um dos interlocutores / debatedores tenta convencer o outro da lógica de seu raciocínio, de sua verdade (no sentido figurado da palavra, já que "verdade" nesse caso é um conceito subjetivo). Enunciados contendo essa visada fazem parte de um julgamento, no qual os advogados de defesa e de acusação de um dado réu travam uma batalha retórica para convencer o júri: com enunciados frutos de raciocínios lógicos bem fundamentados e sabiamente estruturados, e as duas instâncias enunciativas opostas tentam, cada uma ao seu modo, persuadir o juiz e convencer o júri do bien-fondé de seus propósitos. Nessa perspectiva, os enunciados argumentativos visam à persuasão do outro; a sedução e suas artimanhas não são, então, seu objeto. É uma visão mais clássica e utilizada não somente nos tribunais do júri como também pode aparecer em certas publicidades, em debates televisivos, etc. Tenta-se ganhar o outro pela lógica, pelo raciocínio.

Volto, pois, a considerar (MACHADO, 2009, p.110-111) que "a argumentação no discurso se liga tanto aos discursos que visam explicitamente agir sobre o público quanto aos que exercem uma influência, sem ter em vista o desejo de persuadir" (AMOSSY, 2006, p.34).

Explicando melhor: há uma forma de argumentação que se aplica somente a certos tipos de discursos e uma outra, mais ampla, que toca em vários outros. A supracitada autora criou o sintagma dimensão argumentativa para se referir a essa segunda forma de argumentação. Nesse caso, mesmo que a argumentação no seu sentido restrito não seja o objeto de um romance, de uma autobiografia, de um artigo de jornal, etc., ela perpassa tais textos. Assim: 
Nos discursos oriundos de uma conversa familiar, do ensaio, do romance, o locutor não é obrigado a resolver um conflito de opinião [...]. O discurso argumentativo pode propor questôes sobre as quais trabalhou para lhes dar uma certa ênfase e a bem formulá-las, mas não precisa resolvê-las. Este discurso pode submeter um problema à reflexão do auditório sem, no entanto, lhe impor uma solução definitiva (AMOSSY, 2006, p. 35).

No âmbito dessa opção argumentativa, vê-se que o que é buscado, em um discurso ficcional ou semificcional, como o das biografias e outros gêneros que incluem narrativas de vida, é dar ênfase à vida de um ser real, fazendo com que o leitor participe dos temas de reflexão propostos pelo narrador sobre esse sujeito.

Se pensarmos nos modos de organização discursivos (CHARAUDEAU, 1992, p. 631-835), é possível, então, afirmar que os modos narrativo e descritivo contêm índices que levam à dimensão argumentativa. Quando Lula, no livro composto por Paraná (2002), descreve sua infância de menino pobre, faminto, conta como era sua casa, como era sua mãe, como era sua cidade, etc. - enquanto sujeito-falante, ele está dentro de uma modalidade discursiva descritiva (CHARAUDEAU, 1992, p. 653-707) e, no âmbito do livro de Paraná, visto como um todo, essa modalidade entrará ou se encontrará com a modalidade discursiva narrativa (CHARAUDEAU, 1992, p.709-777). A dimensão argumentativa proposta por Amossy (Op. cit.) abrange esse todo, ou seja, a descrição inserida na narração. Atrás da fala sofrida de Lula que nunca se negou a expor seu passado de lutas e sofrimentos, fala que considero como explícita, existe um implícito forte: Deus ajuda a quem nele acredita. Em resumo, nas entrelinhas dessa narrativa de vida, princípios cristãos vão se mesclar a princípios morais. Nesse ponto, Lula sempre constituiu-se em um enigma para os pesquisadores franceses, ${ }^{4}$ que, às vezes, um pouco rapidamente, o criticam por seu populismo. A esquerda francesa não é cristã. Não é fácil para franceses entrar completamente no mundo de Lula: é preciso levar em conta as crenças profundas de um povo e a sua maneira de misturar discursos de um modo fácil, compondo o que Bakhtine (1970) poderia chamar de discurso político carnavalizado.

Voltemos às estratégias argumentativas. Nos livros que se dedicam a personalidades políticas, os já citados Lula e Sarkozy - objeto de nossa atual pesquisa -, existem narrativas de vida em que escutamos a voz daquele que faz a autonarração de sua vida ou às vezes escutamos a voz de um outro, o narrador 
que assume a posição de porta-voz do sujeito objeto da narrativa de vida ou da biografia. Selecionei alguns exemplos:

(i) Tenho que aproveitar a minha origem, de onde eu vim, para não esquecer o problema da fome. Os seres humanos, normalmente, reagem de acordo com o chão que os seus pés estão pisando. [...]. Eu cheguei à Presidência da República, mas não quero esquecer de onde vim, eu não quero esquecer o mundo onde eu convivi politicamente. (LULA, resposta à perguntas feitas na Conferência Anual da Rede Parlamentar de Países-Membros do Banco Mundial, 16/04/2004. In: KAMEL, 2009, p. 499).

(ii) Você quer compreender minha diferença com todas estas pessoas, os Fabius, Juppé e Villepin, sobretudo Villepin que é a quinta essência? É bem simples: eles, desde que nasceram são adulados, protegidos e escutam: "Você é o melhor, o mais belo, o mais inteligente”. Além do mais, eles fizeram estudos brilhantes. [...] Eu, eu sou de outro gênero: eu sou o bastardo. Mas veja só, é o bastardo que é o presidente da República. (SARKOZY, palavras ditas ao jornalista Giesbert. In: GIESBERT, 2011, p.186).

Não deixa de ser curioso verificar que dois políticos completamente diferentes, um da esquerda outro da direita, situados em contextos diferentes, assumam, no espaço de uma quase confissão (sobretudo em (ii), o mesmo tema, que resumiremos da seguinte forma: eu sou o patinho feio, mas sou eu quem manda neste pais.

Analiso tal resumo dos ditos (i) e (ii), seguindo novamente Ducrot (1972, p.171):

Eu sou o patinho feio $\rightarrow$ conclusão $n a ̃ o-p$

Mas sou eu quem manda neste país $\rightarrow$ conclusão $p$

O primeiro segmento do enunciado aponta para uma conclusão não-positiva; o segundo, orientado pelo marcador de oposição mas, aponta para uma conclusão positiva: no caso, é esta a que domina. Tanto Lula quanto Sarkozy têm orgulho de poder afirmar que, mesmo tendo encontrado percalços nos respectivos caminhos, venceram na vida. 
Estou seguindo aqui um princípio que pode ser englobado na dimensão argumentativa dos enunciados. As estratégias que regem tal princípio devem ser buscadas nos operadores argumentativos (como mas), no léxico ("tenho que aproveitar minha origem", "fome", no caso de (i) e "não fiz estudos brilhantes", "bastardo", no caso de (ii), assim como "Presidência da República" - a recompensa para os justos tanto em (i) quanto em (ii)) e na narrativa de vida.

$\mathrm{O}$ que se pode verificar, tanto em (i) quanto que em (ii), é que Lula e Sarkozy evocam fatos de suas vidas passadas, do tempo em que ainda não eram presidentes. Ambos sofreram - Lula, por ser pobre, Sarkozy, pelos seus vários complexos e, entre eles, o de ser filho de um imigrante húngaro. Assim, (i) e (ii) constituem exemplos de um hábil e ousado uso das emoções que vem se mesclar ao discurso político.

Note-se que Sarkozy, ao enunciar (ii), estava se confidenciando a Giesbert; mas ninguém é tão inocente assim: tudo o que se diz a um jornalista pode ser publicado. E ele deveria já saber que Giesbert, como tantos outros, escreveria um livro sobre ele.

Quanto a Lula, a narrativa de vida habilmente exposta em (i) já foi divulgada em discursos de campanha, em uma fala mais espontânea. Lula sempre falou muito sobre suas origens modestas, sobre sua vida difícil ainda como líder do Sindicato dos Metalúrgicos de São Paulo. Sarkozy fala pouco sobre o assunto, mas quando o fez a primeira vez, acredito, ao ter sua candidatura entronizada pelo UMP, em 14 de janeiro de 2007, no Parc des expositions de la porte de Versailles, conseguiu levar mais de um ouvinte do seu auditório às lágrimas. Foram essas suas palavras: "Sou um simples francês de sangue misturado" (GIESBERT, 2011, p. 64).

Sabe-se que as palavras de um discurso viajam de um partido para outro: Sarkozy aqui assumiu um discurso da esquerda, ao dizer que falaria tanto para o burguês rico quanto para o povo. Essas palavras fizeram muitos se lembrar dos discursos de um... Mitterrand! (GIESBERT, 2011, p.64)

A narrativa de vida de Sarkozy encontrou-se como a de Lula com todo um povo.

Não vou discutir sobre a veracidade ou não de tais afirmaçóes: esse procedimento seria longo e desnecessário no espaço deste artigo. Sugiro que as tomemos como asserções nem verdadeiras nem falsas, mas verossimeis. O que está em jogo aqui é saber por que foram colocadas e com quais objetivos, partindo do principio de que nenhum dito é aleatório. Assim, (i) e (ii) podem, sem muito 
esforço, ser considerados dentro de uma dimensão argumentativa: são estratégias que buscam seduzir um auditório respectivo. Os locutores Lula e Sarkozy expuseram, então, suas vidas passadas ou o que pensam de si mesmos. Mas de que lugar foi exposto esse passado ou essa visão interior? De um lugar presidencial, logo imbuído de um principio de legitimidade e credibilidade (CHARAUDEAU, 2005).

Há de se pensar ainda que tal lugar se equilibra sempre entre o estável e o não estável. Há de se angariar a simpatia do público. $\mathrm{O}$ recurso à exposição de sentimentos - caso de (i) e (ii) - ou da inserção em um discurso político de lembranças de uma outra vida, são, sim, estratégias de captação e sedução do leitor e dos eleitores: são estratégias que argumentam, por meio da dramatização de fatos pessoais.

\section{Considerações finais}

No final deste trabalho, não saberíamos bem dizer de forma definitiva, final, o que são enunciados argumentativos. São aqueles formalmente construídos visando a um debate e contendo argumentos lógicos para sustentá-los? Ou tudo o que enunciarmos na vida é dotado de argumentação? Ou ainda que certos fatores podem representá-la? Palavras do léxico com carga axiológica forte? Conectores ou operadores argumentativos? A mistura de diferentes discursos? Nos casos examinados, ficou patente que um discurso vindo de um sujeito-falante político mistura diferentes vozes. Como resolver esse quebra-cabeça?

No que me diz respeito, mantenho a minha adesão a Amossy e a sua divisão da argumentação em visada argumentativa e dimensão argumentativa. As estratégias do discurso objeto de minhas pesquisas sobre a narrativa de vida se prestam de modo admirável a se colar em outros discursos e a melhor politizálos, ao mesmo tempo em que os tornam mais credíveis.

Cabe ainda dizer que a narrativa de vida por si só não pode ser julgada como possuindo uma visada argumentativa. No entanto, ela encerra em seu âmago o desejo de fazer passar uma dimensão argumentativa; ela pode ser observada em certos tipos de textos que misturam efeitos de ficção a efeitos de realidade, tais como: crônicas, telenovelas, filmes, cartas, romances, etc.

Cabe dizer também que a argumentação, nesse caso, permite a eclosão de estratégias que vão se basear em efeitos teatrais - principalmente, como já foi dito, em efeitos de dramatização ou efeitos lúdicos. 
Cabe finalmente inserir a narrativa de vida - no caso de homens políticos - em uma esfera que agrupa diversos discursos: o da pseudoconfidência, o da autoconfiança e, pairando sobre todos eles, o discurso do poder.

\section{Notas}

${ }^{1}$ Todas as citações de livros e revistas franceses foram por mim traduzidas para o português, para este artigo.

${ }^{2}$ Os diferentes sujeitos da enunciação registrados em itálico são provenientes de diversas leituras de Charaudeau (1983, 1992, 2004, 2005) e das interpretações que ele e os membros do Núcleo de Análise do Discurso da FALE/UFMG foram paulatinamente dando aos Eu-comunicante e Eu-enunciador e aos Tu-destinatário e Tu-interpretante do início da Semiolinguística. A denominação sujeito acabou por substituir os pronomes, mas, como eles, visa a ilustrar o jogo enunciativo e seus desdobramentos.

${ }^{3}$ Como exemplo, cito dois livros, ambos de autores franceses: Michel de Montaigne (1595), Essais; René de Chateaubriand (1848-1850), Mémoires d'Autre Tombe. Além disso, a narrativa de vida aparece também inserida no gênero poético: é o caso de um poeta como Manoel Bandeira. Em alguns de seus poemas como Pneumotórax, Porquinho da Índia, Auto-retrato, Bandeira deixa transparecer muito de sua pessoa e de sua vida, fala de sua doença, de sua infância, de suas origens e de sua aparência, sempre sob o tom de uma delicada auto-ironia.

${ }^{4}$ Como pude presenciar em fevereiro de 2009, em Paris XII, em um colóquio sobre a política da América Latina, organizado por Jean-Paul Honoré e Pierre Fiala.

\section{Referências}

AMOSSY, R. L'argumentation dans le discours. 2. ed. Paris: Armand Colin, 2006. ANSCOMBRE, J.-C.; DUCROT, O. Argumentation dans la langue. Liège: Mardaga, 1983.

BAKHTINE, M. L'ouvre de François Rabelais et la culture populaire au Moyen Age et sous la Renaissance. Paris: Tel Gallimard, 1970.

BENAÏM, V.; AZÉROUAL, Y. Carla et Nicolas. La véritable histoire. Paris: Les Editions du Moment, 2008.

CHARAUDEAU, P. Langage et discours. Paris: Hachette, 1983. 
CHARAUDEAU, P. Grammaire du sens et de l'expression. Paris: Hachette, 1992. CHARAUDEAU, P. Ce que communiquer veut dire. Revue des Sciences Humaines, n. 51, p. 20-23, 1995.

CHARAUDEAU, P. Visadas discursivas, gêneros institucionais e construção textual. In: MACHADO, I. L.; MELLO, R. (Org.). Gêneros: reflexões em Análise do Discurso. Belo Horizonte: NAD/FALE/UFMG, 2004, p.13-42.

CHARAUDEAU, P. Le discours politique. Les masques du pouvoir. Paris: Vuibert, 2005.

DUCROT, O. Dire et ne pas dire. Principes de linguistique sémantique. Paris: Hermann, 1972.

GIESBERT, F.-O., M. le Président-Scènes de la vie politique - 2005-2011. Paris: Flammarion, 2011.

KAMEL, A. Dicionário Lula - Um Presidente exposto por suas próprias palavras. Pesquisa ELIAS, R. Rio de Janeiro: Nova Fronteira, 2009.

LOCHARD, G.; BOYER, H. La communication médiatique. Paris: Seuil, 1998.

MACHADO, I. L. Práticas discursivas: construindo identidades na diversidade... e na adversidade. In: GOMES, M. C.; MELO, M. S. S.; CATALDI, C. (Org.). Práticas discursivas: construindo identidades na diversidade. Viçosa: Arca, 2009. p. 103-117.

MAINGUENEAU, D. Analyser les textes de communication. Paris: Dunod, 1998.

MAINGUENEAU, D. Typologie des genres de discours institués version remaniée des pages 180-187 du Discours littéraire, Paris, A. Colin, 2004. (http:// dominique.maingueneau.pagesperso-orange.fr/intro_topic.html)

PARANÁ, D. Lula o filho do Brasil. São Paulo: Editora Fundação Perseu Abramo, 2002.

PROCÓPIO-XAVIER, M. R. Sintese elaborada para a disciplina Teorias do Discurso, ministrada por MACHADO, I. L. no PosLin/FALE/UFMG, $1^{\circ}$ semestre de 2010. SANTOS, J. B. C. Seminário sobre Pêcheux, inserido no curso Teorias do Discurso, ministrado por MACHADO, I. L., no PosLin/FALE/UFMG, $1^{\circ}$ semestre de 2012. 